\title{
Self-Concept Component Study of Tuberculosis Schoolchildren Under Long-Term Treatment in Hospital
}

\author{
Tatiana A. Solovyeva * (a), Irina M. Vitkovskaya (b), Sergey D. Ivanov (c) \\ (a), (b), (c) Pskov State University, 180000, Pskov (Russia), 2 Lenin square, \\ tatsolovyova@yandex.ru
}

\begin{abstract}
The relevance of the study of this problem is explained by the fact that the schoolchildren with tuberculosis undergoing long-term treatment make up a large group of students with special educational needs. In the interests of social justice and equal opportunities to realize their personal potential, these students need special learning conditions being created, such as special teaching methods, as they experience pronounced difficulties in socio-psychological adaptation and integration into the educational environment.

The aim of the article is to provide theoretical substantiation and experimental research of the cognitive, emotionalvalue and behavioral-volitional components of the self-concept of the schoolchildren with tuberculosis undergoing long-term treatment.

The conducted research is based on the methods of theoretical analysis of domestic and foreign literature sources, testing of 50 students with tuberculosis, qualitative and quantitative analysis of the results of their self-reflection.

The article presents a meaningful characteristic of the pedagogical aspect of the structural components of the category "self-concept" of a student who is on long-term treatment.

Empirically, it has been found that more than half of the tested tuberculosis schoolchildren (52\%) have elevated, high and very high levels of: resentment, negativism - 56\%, physical aggression - $64 \%$, sense of guilt - $72 \%$, suspicion $76 \%$, irritation - $84 \%$, verbal aggression - $96 \%$.

The practical significance of the research results presented in the article is that the results of the tuberculosis schoolchildren under long-term treatment will help teachers better understand and prevent possible problems in their education.
\end{abstract}

Keywords: schoolchildren with tuberculosis undergoing long-term treatment; cognitive, emotional-value, behavioralvolitional components of the self-concept of schoolchildren; diagnostics of the self-concept of the schoolchildren studying at hospital schools.

(C) 2020 Tatiana A. Solovyeva, Irina M. Vitkovskaya, Sergey Ivanov

This is an open access article distributed under the terms of the Creative Commons Attribution License (CC BY 4.0), which permits unrestricted use, distribution, and reproduction in any medium, provided the original author and source are credited.

Published by Kazan federal university and peer-reviewed under responsibility of IFTE-2020 (VI International Forum on Teacher Education)

\footnotetext{
* Corresponding author. E-mail: tatsolovyova@yandex.ru
} 


\section{Introduction}

The schoolchildren with tuberculosis undergoing long-term treatment are constantly in stressful situation, as they do not only worry about their serious illness, but they are also separated from their relatives, usual learning environment, they are forced to build new interpersonal relationships and to adjust their selfconcept. It is the modifications of the self-concept that transfer them into the group of the children with special educational needs, which should be taken into account in the educational activities organized in hospital schools.

\section{Purpose and objectives of the study}

Purpose of the study is to provide theoretical substantiation and experimental research of the cognitive, emotional-value and behavioral-volitional components of the self-concept of the schoolchildren with tuberculosis undergoing long-term treatment.

\section{Literature review}

The analysis of the scientific literature sources dedicated to the study of the category of "self-concept" shows that until now there has not been an unambiguous approach to its view and definition. Each approach has made a certain contribution to the formation of the notion of "self-concept", considered by most researchers as a central formation in the structure of personality and personal adaptation.

The theoretical analysis conducted has made it possible to base our research on the following scientific approaches.

- The approach of Rogers and Freiburg, who interpret the self-concept as a mechanism that controls and integrates the behavior of an individual, the most important determinant of responses to his environment (Rogers, 2001), as an integral system of self-perceptions of an individual, formed in the process of his socialization (Rogers \& Freiburg, 2002).

- The multi-level scheme of the "self-concept", proposed by the English psychologist Burns (2012, p. 41), according to him "the "self-concept", in essence, determines not just what an individual is, but also what he thinks about himself, how he views his active initiative and the possibilities of development in the future".

Due to the fact that Burns considers "the "self-concept" as a set of attitudes directed at one own self" (Burns, 2012, p. 41), and any attitude includes cognitive (belief), emotional (attitude) and behavioral (reaction) components, cognitive, emotional-value and behavioral-volitional components can be identified 
in the structure of the self-concept of a tuberculosis schoolchild. Resting on Burns' approach, it can also be argued that the self-concept of an tuberculosis schoolchild, although it is a "relatively stable mental acquisition", at the same time "is subjected to internal changes and fluctuations" under the influence of external factors in the process of social interaction.

- In our research we also rely on the views of Epstein (1973), who experimentally proved that the selfconcept is constructed by an individual on the basis of his life experience, including traumatic one. Epstein (1973, p. 404-416) named the establishment of a positive balance "pleasure-pain" as one of the three unique functions of the self-concept which is especially important in the study of the self-concept of tuberculosis schoolchildren.

In this regard, Kogan's idea (1983) about the need to gradually overcome an individual's fixation on pathological experiences and create the necessary conditions for the harmonization of the personality and his self-consciousness, acquires special significance for us.

- In scientific literature extensive material indicating that children with various diseases have deviations in the formation of their self-concept has been accumulated. In particular, the conclusion of Vygotsky (1984) that the presence of any defect provokes a number of secondary changes in the development of personality.

In practical pedagogical work with students who are under long-term treatment and have modifications in their self-concept, it is necessary to take into account the opinion of Gribanova (1986) that children with unstable and immature self-esteem are more sensitive, have elevated suggestibility, lack of independence and unstable behavior. Martsinkovskaya's idea (2009, p. 228) that a student's vague idea of himself "is experienced by a person as uncertainty or, on the contrary, self-assurance, generates the functioning of numerous psychological defenses and forms of protective behavior". Belyakova's assumption (1996) that self-esteem, namely an individual's awareness of a sense of inferiority, acting as an individual's "motivator", helps him go in search of solutions to compensate for the defect.

\section{Methodology}

The methodological basis of the research is the acmeological approach to teaching schoolchildren according to individual educational trajectories (Solovyeva \& Makarchuk, 2018); the position of the American scientist Rodriguez (2000) on assimilating the experienced tragic events into a positive life experience that makes an individual stronger; the analytical conclusion of Professor Ludwig of the University of Kentucky (USA) (Ludwig, 1969) that for the transformation of giftedness into talent, mental tension is also necessary, including emotional experiences, shocks, and diseases. 
The conducted research is based on the methods of theoretical analysis of domestic and foreign scientific literature sources; diagnostic (testing of 50 schoolchildren with tuberculosis); praxiometric (qualitative and quantitative analysis of the results of their self-reflection); methods of mathematical processing and graphical representation of the results.

The empirical part of the study was conducted from 2017 to 2019 on the basis of the federal state budgetary scientific institution "Central Research Institute of Tuberculosis" in Moscow.

The research was conducted in three stages. Theoretical analysis of existing scientific literature sources in domestic and foreign psychological and pedagogical literature dedicated to the study of self-concept was carried out; the problem, aim, and methods of research were defined, the plan of the empirical research was formulated during the first stage of the research. At the second stage, the empirical study of the three components of the self-concept of tuberculosis schoolchildren was carried out using psychological questionnaires and tests. At the third stage, optimal learning strategies and special conditions for the organization of educational activities of schoolchildren were predicted and justified.

\section{Results}

Content characteristic "Self-concept" of a student under long-term treatment".

Let us present the results of the theoretical research of the pedagogical aspect of the structural components of the category "Self-concept" of a student under long-term treatment".

- The cognitive component of a sick schoolchild "self-concept" is a "critical self-image "which includes the content of his ideas about himself, the results of understanding of his position, motivation for learning, self-assessment of his current capabilities, conditions for the ability development, social significance and place among healthy people and people as sick as himself. The cognitive component of the self-concept of sick schoolchildren is reflected in the level of self-demand, perseverance and attitude to their successes and failures in educational activities.

- The emotional-value component of the self-concept of a sick student is a personally significant reflection of the student's self in the educational environment, the experienced attitude to himself in general and to his health in particular; ranking of the system of terminal and instrumental values in the current situation.

- The behavioral-volitional component of the self-concept of a sick schoolchild is characterized by the manifestation of cognitive and emotional-value components in behavior. Volitional efforts of a sick student 
in educational activities are a "form of emotional tension, stress" that mobilizes his perception, thinking, imagination and memory, creating additional meanings of learning, motives for performing educational actions that were either absent or insufficient.

\section{The empirical component of the research.}

To identify optimal learning strategies and justify special conditions for the organization of educational activities of schoolchildren who are not only in long-term isolation from their families, but also experience mental suffering from the severe illness, asking a "mute" question "Why is it happening to me?" it was necessary to conduct the empirical research of the components of tuberculosis students' self-concept, using psychological tests.

The cognitive component of the "self-concept", as its central component, includes such a characteristic as self-attitude or self-acceptance (friendliness - hostility to one's own "self").That is why the method of Stolin (1983) and Pantileev (1993), which allows using a questionnaire to determine the index of selfacceptance on a scale consisting of 16 points, was chosen to be the first diagnostic method. In terms of content, this scale on the positive pole corresponds to an unconditional acceptance of one's own self, even with some shortcomings; on the negative pole, it is a vision of oneself as a person with a lot of shortcomings, low self-esteem, and an inclination to self-blaming.

This test was used by us in the first two months of students' stay at the "Central Research Institute of Tuberculosis" in Moscow. It showed that a low level of self-acceptance was observed in $4 \%$ of the sick children, below average-in $20 \%$ of the students, average-in $40 \%$, above average-in $16 \%$, high-in $20 \%$ of the children surveyed.

The levels of self-acceptance shown by the children at the ascertaining stage of the experimental work are presented in the diagram in Figure 1 (Fig. 1). 


\section{Self-acceptance levels (in percentage)}

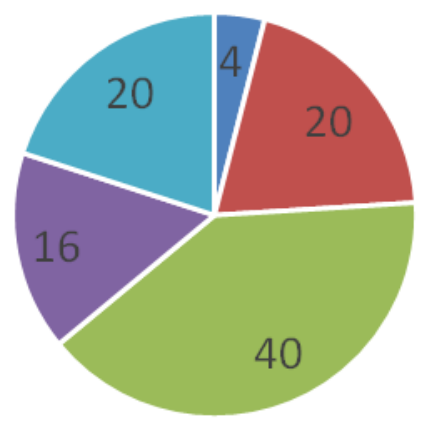

- Iow

\section{- below average average above average}

nigh

Fig. 1. Results (in levels) of manifestation of sick children self-acceptance at the ascertaining stage of the experiment

Thus, the levels of "low" and "below average" were observed in $24 \%$ of children with tuberculosis. These students had cognitive reactions to themselves that consisted of making self-reproaches ("you deserve it"), self-mockery, being aware of irritation against themselves, and judging their own weaknesses. On the background of low self-esteem of their current capabilities, every fourth sick schoolchild had an increased level of strictness, exactingness and self-demands.

The second component of the "self-concept" is an emotional-value component based on the emotional memory of a child, which includes intellectual memories of affective states, that is, a set of subjective (negative and positive) experiences fixed in the memory about events significant for the subject, the experienced attitude to oneself in general and to one's own health in particular.

In this regard, during the second diagnostic section of the "self-concept" of the students participating in the survey, the method "My saddest and most cheerful (happy)" was used.

It turned out that $28 \%$ of the surveyed children (14 people) with tuberculosis keep in their memory, as the saddest and tragic the day when they learned about their disease: "In my life, there is the saddest story that I got sick with tuberculosis and I am in a tuberculosis hospital. And the most interesting and fun thing will be that I will be cured and become a doctor. And I will never get sick with tuberculosis!" (Ksenia A., $8^{\text {th }}$ grade); “But I also have a problem: I ended up in hospital... but it's good that I'm not alone here, just like at home: friends, school, teachers, all of them are very kind and good" (Karina A., $7^{\text {th }}$ grade). 
The children's negative emotions associated with their illness are very strong. So, Albina I. (7th grade) writes: "When I am adult, I want to forget about these worries".

A certain number of children (24\%) are very sad due to a long stay in hospital: "The saddest moment of my life was when I was at home and I was told that I would be in hospital for six months. I had a tantrum" (Albina I., $7^{\text {th }}$ grade); "But the saddest memory is when I went to hospital for the first time. It was the first time I was so far from home, from my parents. Then it was very hard" (Kristina Ch., $8^{\text {th }}$ grade); "My sadness is that I haven't been at home for almost a year" (Erica Sh., $6^{\text {th }}$ grade).

It is important that some of the children interviewed associate the joy of their life with treatment in a specialized Moscow clinic: "My joy is that I am being treated in this hospital. Yes, it is certainly far from home, but I will endure! In this wonderful hospital, I will definitely be cured and I will fly home! There are very good doctors here, and I will recover quickly" (Erica Sh., $6^{\text {th }}$ grade).

$12 \%$ of the children (6 people) believe that the death of their relatives (father, mother, sister, grandmother) is the saddest event of their life: "My dad died two years ago. He had tuberculosis just like me, but he didn't take pills and didn't want to go to hospital. His mother told him to stay at home. Since then, my life had turned into hell, coming from school, I watched him suffer, fed him. He screamed with pain when my mother washed him, and I was doubly hurt. When he was gone, I stopped trusting people and don't trust them anymore" (Anastasia K., $9^{\text {th }}$ grade); "The saddest thing in my life is the death of my younger sister. I was sad and cried for every longtime" (Kristina Ch., $8^{\text {th }}$ grade); "The saddest thing I had in my life was when my grandmother died" (Karina A., $7^{\text {th }}$ grade).

The study of the emotional-value component of tuberculosis schoolchildren required conducting a research on the basis of the "system of terminal and instrumental values" ranking (Rokich's terminology, 1973).

Such terminal values (that is, the goals of individual existence, which from a personal point of view are worth striving for) as "life" and "health" were in the first place in importance for sick schoolchildren (84\%).In the second place, the surveyed students put "knowledge", "friendship", "happiness" and "beauty" (70\% of the choice). The third rank was assigned by children to such values as "reliable family" and "security and peace" ( $56 \%$ and $42 \%$ of elections, respectively). The terminal values "pleasure, comfortable life" and "hope" were in $4^{\text {th }}$ place with $28 \%$ of the choice. "Recognition, respect" and "justice" were even less significant (rank 5, 14\%) for tuberculosis schoolchildren. This distribution of the terminal values by tuberculosis school children in their current situation seems obvious.

As for the ranking of instrumental values by this group of students (that is, personal traits preferred for a person in any situation), the picture was as follows. The first rank was assigned to emotional and strong- 
willed personal qualities - "responsibility" and "self-control" (choice of 70\%) and values related to the character of an individual - "cheerfulness" (the choice of 68\%).Two emotional and strong-willed personal qualities - "strong will" and "tolerance" (64\%), as well as the values of education - "accuracy" and "politeness" (64\%), were in the second rank in terms of the number of the choices."Obedience" and "efficiency", based on the choice of the students with tuberculosis, were assigned to the fourth rank (20\%). The fifth rank was given to "ambition", "independence, having your own opinion" and "intransigence to your shortcomings" ( $8 \%$ choice).

The third, behavioral-volitional component of the "self-concept", which characterizes the manifestations of cognitive and emotional-value components in the behavior of tuberculosis schoolchildren, was determined by using the Buss-Durkey aggression test and the "Self-description of the self-image in the future" method. The combination of these two methods is explained by the fact that aggression, as a property of a personality, and aggression, as an act of behavior, can be understood precisely in the context of analyzing the need-motivational sphere of the personality of sick schoolchildren.

We adhere to the psychological theory that hostility is the result of frustration, understood as the consequence of the gap between expectations and the actual current situation. In the presence of agents of aggression, hostility can provoke aggressive actions in sick schoolchildren.

In our research we identified the value of the hostility index in schoolchildren who are under long-term treatment for tuberculosis, calculated using a variant of the Buss-Durkey method adapted by Rogov (2020), according to whom "hostility = resentment + suspicion". According to this method, the test results were interpreted as follows: the norm of hostility is the value of its index equal to 6-7 \pm 3 .

The results obtained in our experimental work for determining hostility in schoolchildren with tuberculosis are presented in the diagram in Figure 2(Fig. 2). 


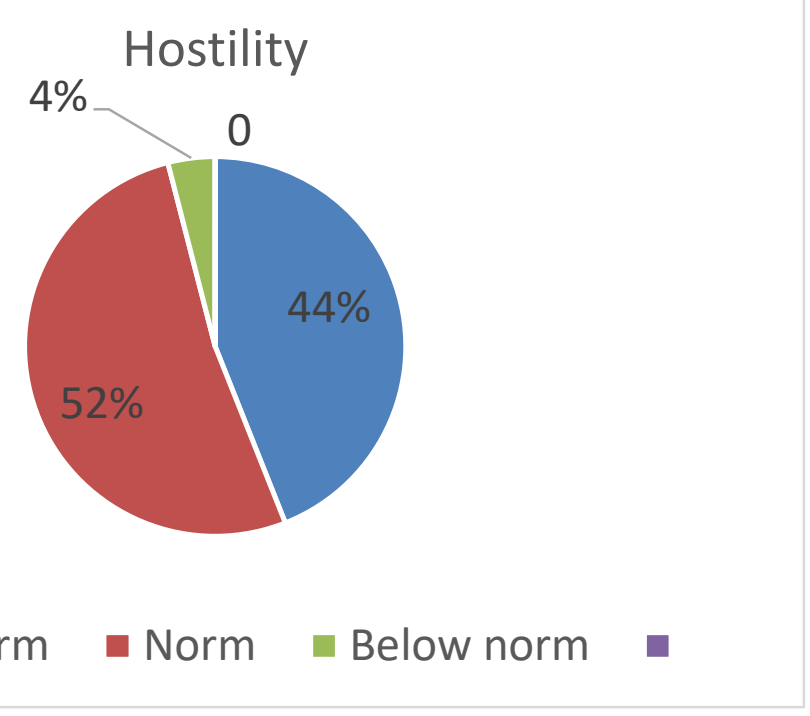

Fig.2. Diagram of the hostility of tuberculosis children undergoing long-term treatment

As can be seen from the diagram in Figure 2, 44\% of the schoolchildren who have tuberculosis and are accepted to the clinic for long-term treatment have hostility above the norm.

The levels of various forms of aggressive reactions (resentment, suspicion, physical and verbal aggression, irritation, negativity, and guilt) of the tuberculosis schoolchildren were calculated using the methods of Buss-Durkey, modified Khwan et al. (2006). In Figures 3, 4, 5, 6, 7, 8, 9 these results are presented graphically in histograms.

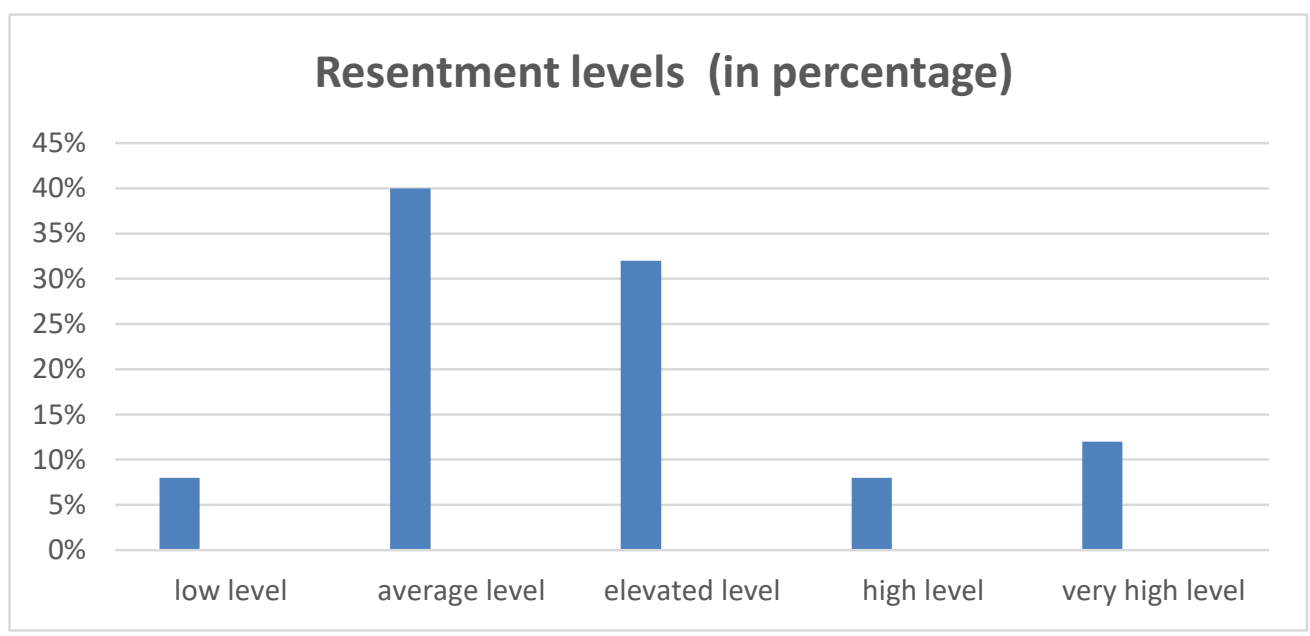

Fig.3. Histogram of resentment levels of the tuberculosis schoolchildren undergoing long-term treatment 
As can be seen from the histogram in Figure 3, more than half (52\%) of the tuberculosis schoolchildren aged from 12 to 15 years old undergoing long-term treatment have elevated, high and very high levels of resentment, i.e. envy and hatred of others for real and fake actions.

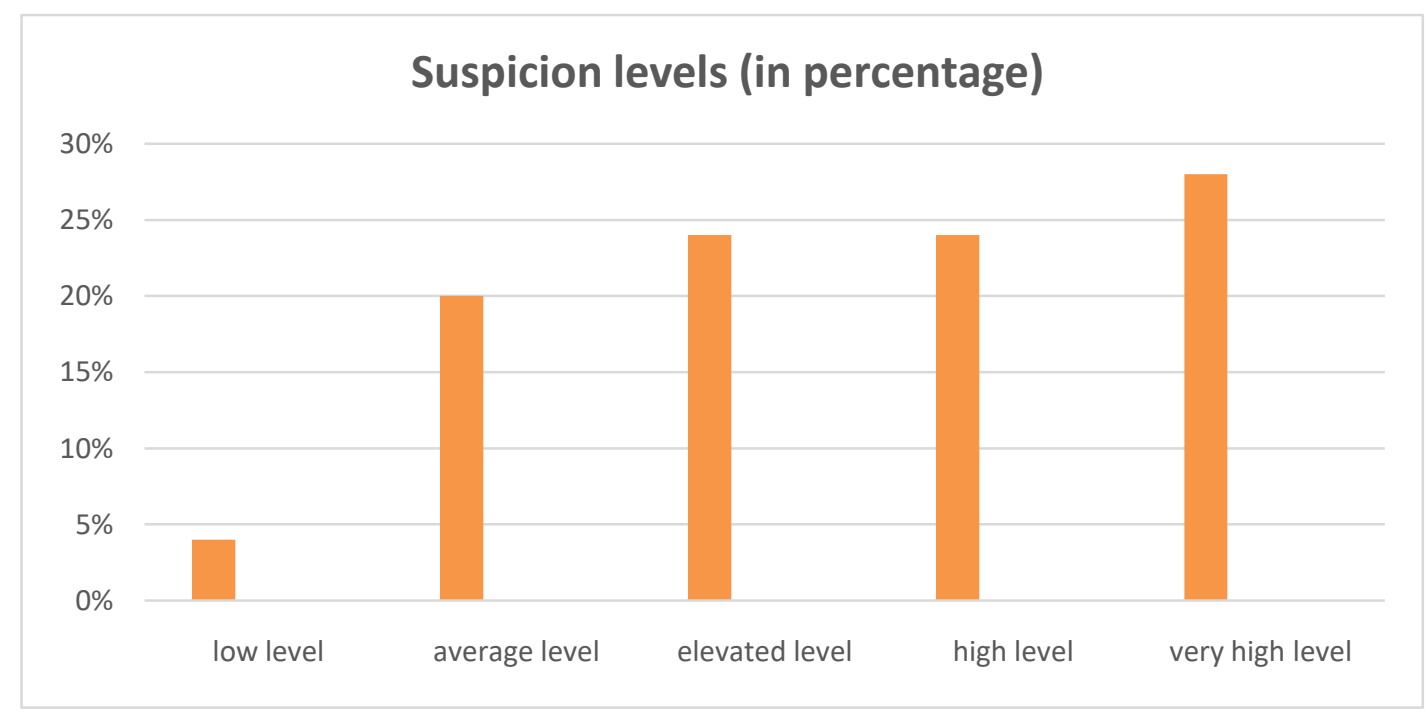

Fig.4. Histogram of suspicion levels of the tuberculosis schoolchildren undergoing long-term treatment

The histogram in Figure 4 shows that $76 \%$ of the tuberculosis schoolchildren have elevated, high and very high levels of suspicion, which ranges from distrust and caution towards people to the belief that other people are planning and causing harm. 


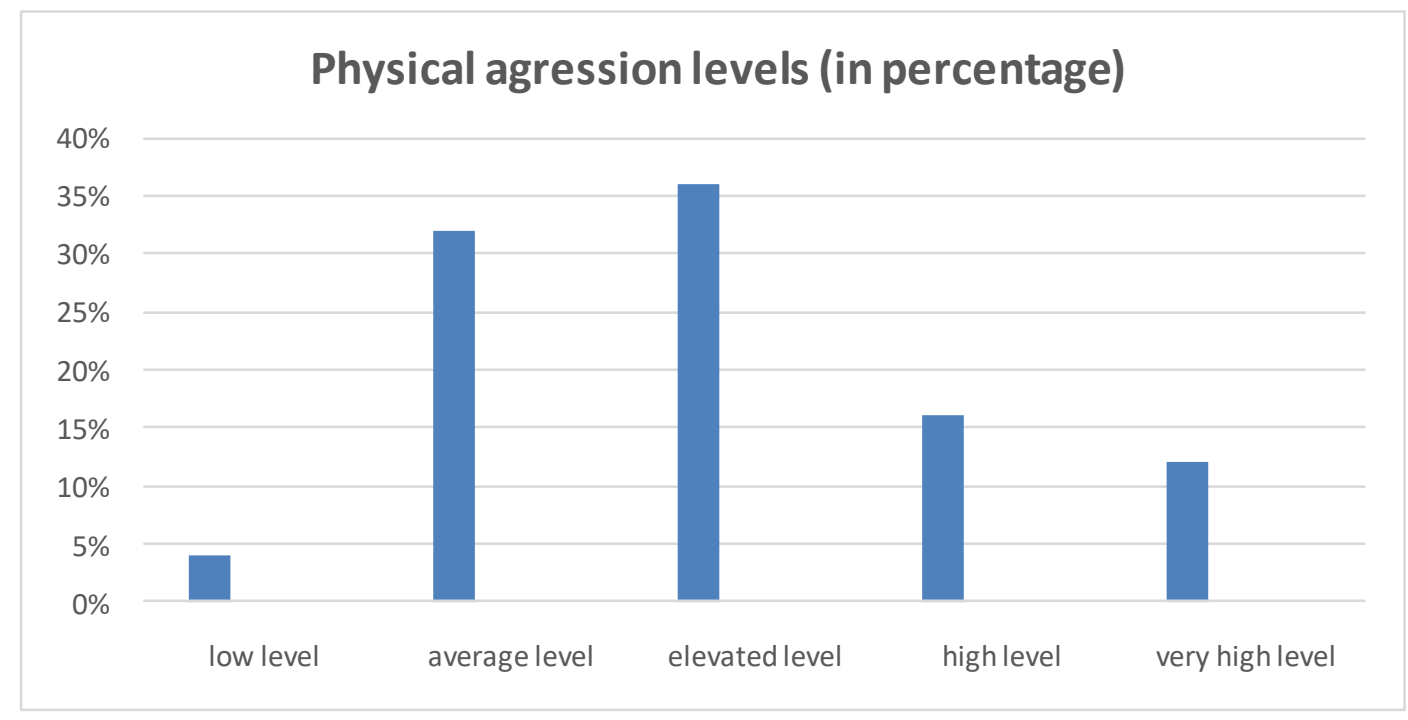

Fig. 5. Histogram of physical aggression levels shown by tuberculosis schoolchildren undergoing long-term hospital treatment

The histogram in Figure 5 shows that $64 \%$ of the tuberculosis schoolchildren have elevated, high and very high levels of physical aggression.

Verbal aggression, i.e. the expression of negative feelings both through the form (shouting, screeching) and through the content of verbal responses (curses, threats) in $96 \%$ of the schoolchildren with tuberculosis who were accepted to the hospital for treatment, is at elevated, high and very high levels (Fig.6).

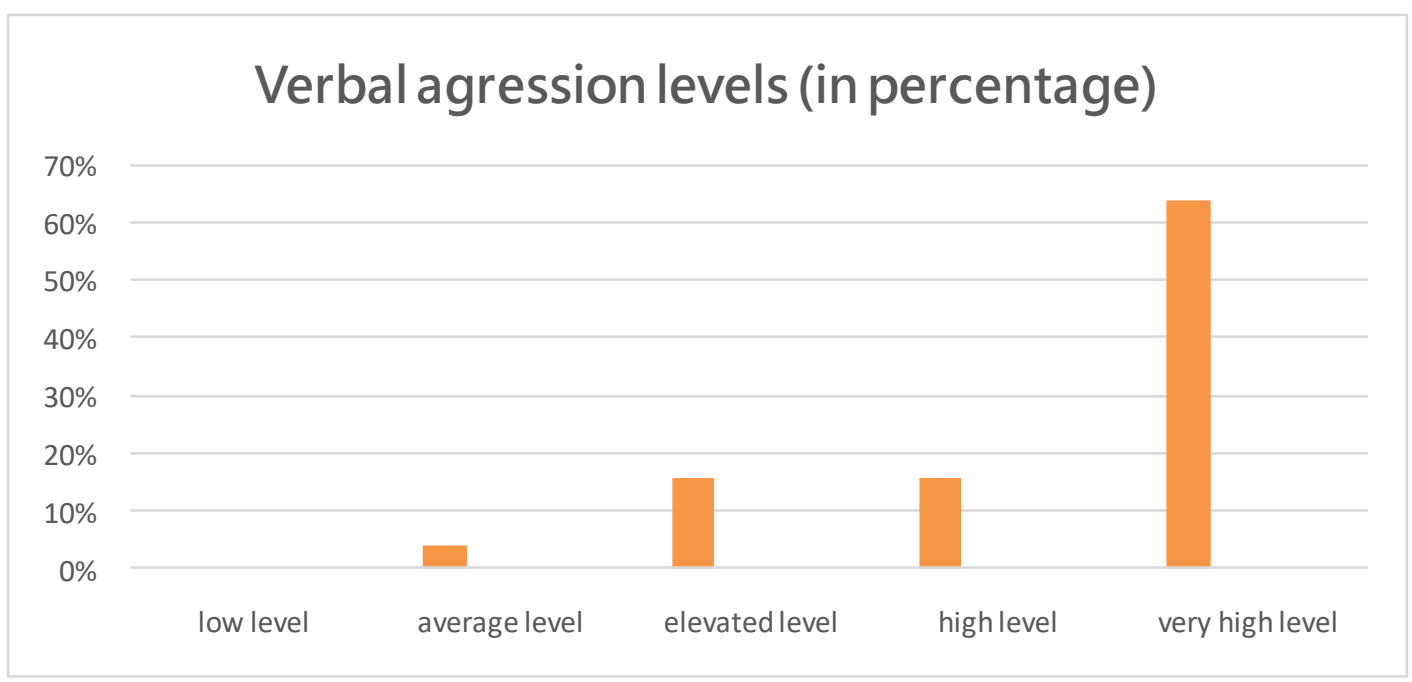


Fig.6. Histogram of verbal aggression levels shown by tuberculosis schoolchildren undergoing longterm treatment

Irritability, that is, readiness to show negative feelings at the slightest excitement (short temper, rudeness), $84 \%$ of schoolchildren who are under long-term treatment, is at elevated, high and very high levels (Fig.7).

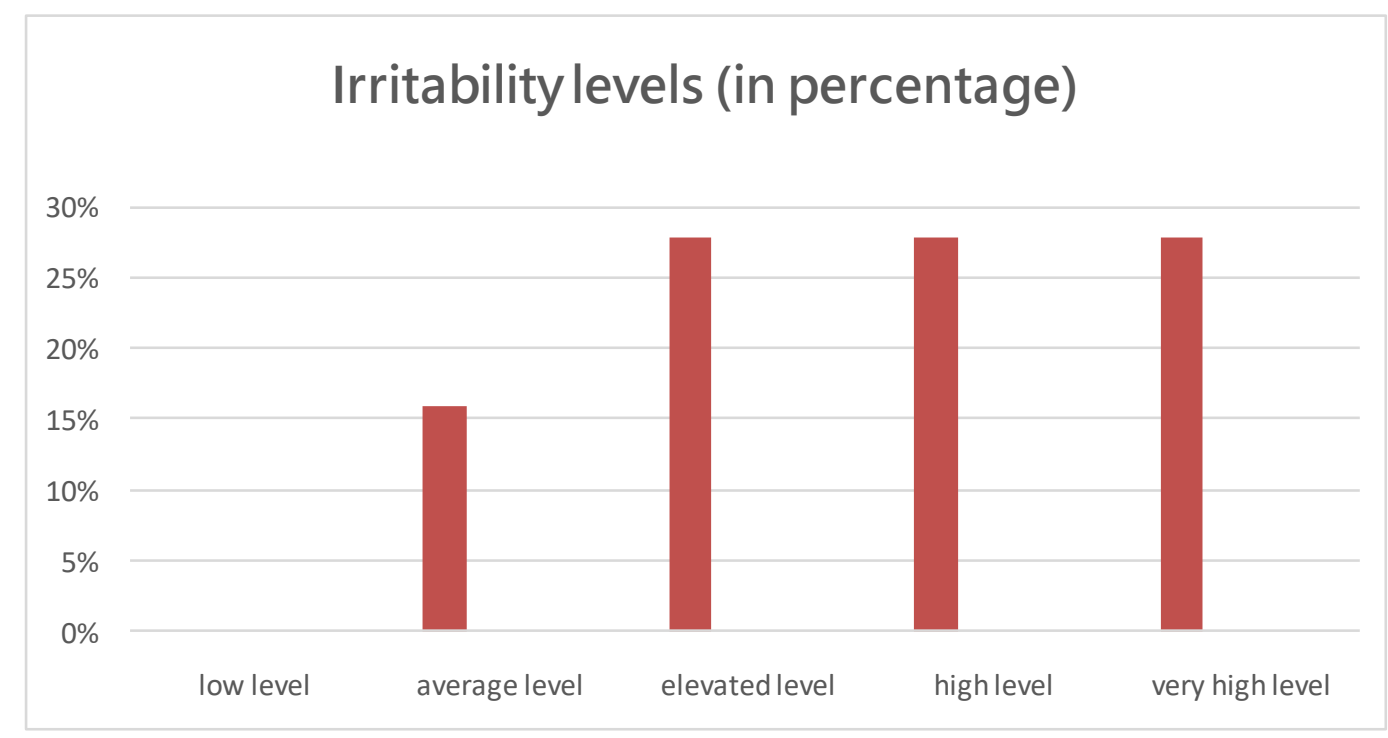

Fig.7. Histogram of irritability levels of the tuberculosis schoolchildren undergoing long-term treatment

The feeling of guilt, which expresses the possible belief of a sick schoolchild that he is somehow to be blamed for the current situation, was observed at elevated, high and very high levels in $72 \%$ of the children (Fig.8). 


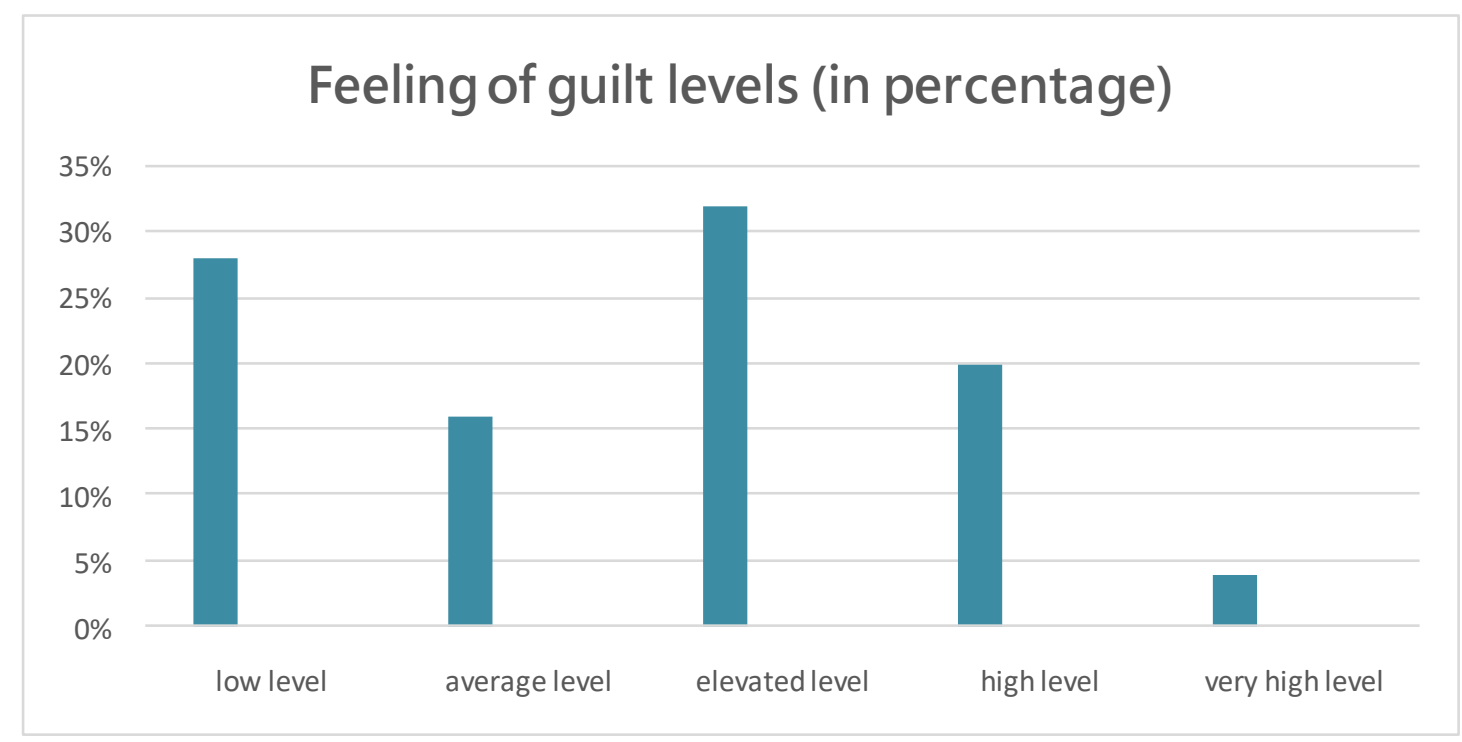

Fig. 8. Histogram of feeling of guilt levels of the tuberculosis schoolchildren undergoing long-term treatment

Negativism, in other words, the oppositional manner of behavior of the sick schoolchildren from passive resistance to active struggle against customs established in the hospital, new school for themis observed in $56 \%$ of the children (Fig.9).

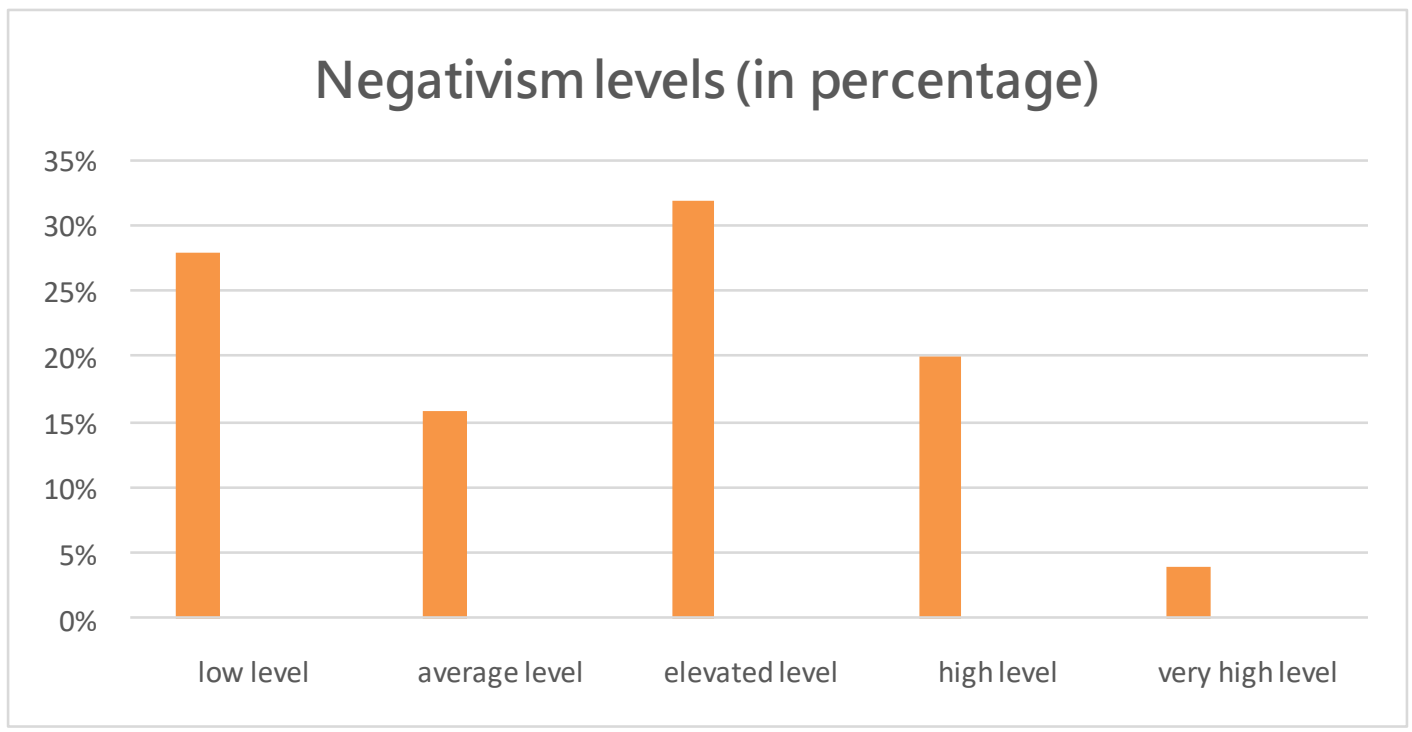

Fig.9. Histogram of negativism levels of the tuberculosis schoolchildren undergoing long-term treatment 
For the empirical study of the behavioral-volitional component of the self-concept, which contains, among other things, the views of tuberculosis schoolchildren on their active initiative and opportunities for development in the future, they were asked to write a short essay "I and my future".

Mathematical processing of the results of their self-reflection through this essay showed that only $12 \%$ of children among tuberculosis schoolchildren are pessimistic about the future. Here are the lines from the essay by Danila V. (9 ${ }^{\text {th }}$ grade): "When I think of the future, I get scared".

$44 \%$ of schoolchildren are optimistic about their future. Below are the excerpts from the essays of the tuberculosis schoolchildren aged from 12 to 16 years who are under long-term treatment.

Many students hope for the best and believe that their stay in hospital has "hardened" their character. Thus, AlinaYa. (8th grade) wrote: "I am sure that my future will be good, as I will try to do everything possible to make my dreams come true. Yes, there will be many difficulties, I know and understand this, but trials only make us stronger".

"It seems to me that our generation has a great responsibility to develop the country, to remember the values that, unfortunately, have begun to be forgotten in modern society. Whatever surprises fate has prepared for me, I will stay a good person" (Anastasia K., $9^{\text {th }}$ grade).

"I don't know how my life will turn out, but I will try my best to get education, find a good job and not to waste time" (Alina Ya., $8^{\text {th }}$ grade).

"People don't go to the future, they create it through clear thoughts in the head and the skill of material creation acquired in life. An incredible amount of thoughts in the head, they need to pass through the subconscious filter, highlight the important, and slowly get down to business. Perhaps such goals are the "flashes" of our future. It remains only to set a goal. The future is in our hands. Life is single, so let's not miss this moment of creation" (Tamara A., $10^{\text {th }}$ grade).

$44 \%$ of the children studying at the hospital school are also neutral about their future. Some children associate their future only with their discharge from the hospital. "When I get out of the hospital, I will go to a sanitarium, and then I will go home, meet my parents and friends, go to school. And I will hope that I will never go to hospital again" (Kristina Ch., $8^{\text {th }}$ grade). "I will be discharged from the hospital and continue to live like normal people. I will walk with my friends, go hiking with my classmate sand go to the sea with my parents. And then I will just live" (Karina A., $7^{\text {th }}$ grade).

Many tuberculosis students associate their future with the choice of a particular profession. Here are the lines from the essay by Danila V. $\left(10^{\text {th }}\right.$ grade): "If I were asked: "How do you see yourself in a couple of 
years?", then I would answer "a stock magnate who owns a couple of brokerages". In fact, it would be nice to move to the village and become a tractor driver. Get up at dawn and roll out into the fields under the crimson rays of the sun. ... And there is no mad pace of concrete labyrinths in these lands, only peace, work and nature".

It is impossible not to pay attention to the fact that the vast majority of the sick children are planning to become a doctor or nurse in the future. "The profession of a doctor is a popular profession, because a doctor is a person who can work a miracle. After all, saving a person from death is really a miracle...... also dream of becoming a doctor, I do not mind that it will take a very long time to get this profession. Of course, this work is very difficult and responsible, but I am not afraid" (Ksenia A., $8^{\text {th }}$ grade).

"I want to go to medical college, although I know that this is not an easy profession, but I am not afraid of difficulties". (Kristina N., 6 ${ }^{\text {th }}$ grade). "At 18 I will go to medical school" (Yulia O, $7^{\text {th }}$ grade). "While in hospital, I realized that I want to connect my life with medicine. We need to help people recover from tuberculosis. I can't become a doctor. Not enough knowledge and abilities. But I will become a nurse" (Vika K., $8^{\text {th }}$ grade).

\section{Educational recommendations.}

The organization of educational activities at school that operates in the hospital for the treatment of tuberculosis children should take into account the modifications of the self-concept of the sick students.

Pedagogical optimism is inspired by the fact that for the students of this group, "knowledge" and "education" took the second place in the rating of terminal values. In order to support the attitude towards education as a personal value in tuberculosis students, a hospital school should become the so-called "acmeological school" for them. At this school, learning should be made a desirable and enjoyable activity with an individual educational trajectory.

We interpret the concept of "acme" not as the final point of life movement and development, but as the peak from which new "horizons" of further movement can be opened for the student at this age stage of development. This is not the achievement of a pre-marked bar, but a continuous movement towards selfimprovement and intellectual self-actualization. Intellectual self-actualization, that is, performing intellectual activity because "I want" it, at the maximum level at which "I can", and receiving intellectual satisfaction, intellectual joy, will "extinguish" the agents of aggression in the educational process and reduce negativism.

To ensure intellectual self-actualization of the students who are under long-term treatment in hospital, 
hospital school teachers should use the author's technology of intellectual development training in the educational process (Solovyeva, 2000), the leading methodological idea of which is as follows. If we divide educational information into logical elements, construct complexes of developing tasks based on them, and ensure the "acceptance" and success of their implementation by the students due to the anticipation of the result, then not only deep understanding of educational information by students is guaranteed, but they form new meanings of learning and subjective goals that are worth striving for from a personal point of view. The implementation of the technological principal of external and internal indirect pedagogical correction due to the systematic repetition of the types of developmental tasks will reduce tuberculosis schoolchildren from internal irritation of the expected failures ("I was sick, fell behind at school, now I find it hard to learn").

To implement the principle of success in teaching children with special educational needs, which include the tuberculosis students undergoing long-term treatment, it is advisable to take into account the intellectual and psychological gender of the student, which does not always coincide with his biological sex. We view the intellectual-psychological gender of a student as a "part of the psychological substructure of an individual, characterizing the behavior of need for training of mental processes (sensations, perception, thinking, imagination, needs, motives, emotions, etc.) arising from bio-genetic program of individual development" (Solovyeva \& Shiryaykina, 2015, p. 197).

When organizing educational activities of the students with intellectual femininity, it is important to remember that it is recommended for them to be asked to perform tasks according to a pattern or a template, since they spontaneously manifest their main intellectual motive - "the tendency to create by analogy".

The students with intellectual masculinity are characterized by an elevated need to get new impressions; they are prone to search activities, to invent something new; it is easier for them to work with schemes. These children perform logical tasks and tasks for establishing compliance without stress. Since they tend to "want to get out of control", it is advisable for them to increase the volume of independent tasks.

The teacher's consideration of the leading modality of children's perception (visual, auditory, kinesthetic) can have a positive impact on the success in teaching tuberculosis schoolchildren in hospital. It is known that when the information given orally or in writing does not correspond to the leading system of perception of a student, he is forced to "translate" it into his own language. While he is busy "translating", much of the training information "passes by". So, it is desirable that a teacher creates a handout didactic material for independent work, taking into account the sick student leading modality of perception. 
Considering that tuberculosis students also put "friendship" to the second position among the terminal values, therefore, it is desirable to plan during extracurricular activities to perform tasks in pairs and friendly groups, allowing even "fraternity".

When teaching sick children under long-term treatment in hospital, it is necessary not only to activate reserve energy and intellectual capabilities, but also to regularly correct their psycho-emotional state during training sessions: conduct psycho-emotional discharges and "moments of rest", neutralizing negative effects in cases when it is not possible to completely protect a sick schoolchild from them.

\section{Discussions}

As before, the issue of determining the essential features and structure of the "I-concept" category remains debatable due to the lack of a methodologically holistic position and some terminological confusion of the use of this term.

Most studies are aimed at studying only certain components of the self-concept, such as self-awareness, self-esteem. In the study of the integral structure of the "I" basically two approaches are presented: hierarchical and taxonomic (classified). The most convenient for solving pedagogical problems, in our opinion, is a multi-level model of the self-concept of Burns (2012), which was the methodological basis for our study.

\section{Conclusion}

Thus, the components of the "self-concept" can include: cognitive, emotional-value and behavioralvolitional components that are closely related to each other.

The cognitive component of the self-concept of a sick student includes the results of understanding the motives, additional meanings for further training (the desire to become a doctor or nurse), awareness of the value of health, life and knowledge.

$24 \%$ of the children with tuberculosis have low and below average levels of self-acceptance, that is, friendliness-hostility to their own "self". For these students, cognitive responses to themselves consisted of making self-reproaches ("you deserve it"), self-mockery, being aware of irritation against themselves and condemning their own weaknesses.

The empirical study of the emotional-value component of the students undergoing long-term treatment showed that $64 \%$ of the children put such emotional-volitional personal qualities as "strong will" and "tolerance" in the second, and "responsibility" and "self-control" in the first place (70\%) for themselves. 
The behavioral-volitional component of the self-concept of a sick schoolchild is characterized by the manifestation of cognitive and emotional-value components in behavior.

$44 \%$ of the schoolchildren with tuberculosis who are admitted to the clinic for long-term treatment have hostility above the norm, as a result of frustration, understood as the consequence of the gap between their expectations and their actual current situation.

The analysis of the results of diagnosing aggression as an act of behavior has revealed that more than half $(52 \%)$ of the tested tuberculosis schoolchildren in the first two months of their stay in hospital have elevated, high and very high levels of resentment, negativism - 56\%, physical aggression-64 \%, guilt-72\%, suspicion-76\%, irritation-84\%, verbal aggression-96\%.

Reducing the effects of these negative factors becomes possible if teaching in a hospital school is made a desirable and enjoyable activity, building an individual educational trajectory for every tuberculosis student, aimed at the intellectual self-actualization of a student. Using the technology of intellectual development training in the organization of educational activities will ensure the success of teaching (due to the anticipation of the result with the help of hidden hints) and eliminate the lag in learning (due to external and internal pedagogical correction).

Special educational needs of the tuberculosis schoolchildren are explained by the recommendation to take into account their intellectual and psychological gender and the leading modality of children's perception, as well as their psycho-emotional state regular correction.

The research only outlines the approaches to solving the problem of choosing optimal strategies and means of teaching tuberculosis schoolchildren based on the study of the components of their "self-concept".

\section{References}

Belyakova, E. G. (1996). On the issue of self-relationship in the structure of the personality of a disabled person. Problems of social and psychological-pedagogical rehabilitation of disabled people: proceedings of the international congress. Tyumen, December 2-5.

Burns, R. (2012). The development of "I-concept" and education. Moscow: Izdatel'stvo «Progress».

Epstein, S. (1973). The self-concept revisited, or a theory of a theory. American Psychologist, 28, 404-416. 
Gribanova, V. G. (1986). Psychological characteristics of the personality of a teenager with mental retardation. Defectology, 3, 13-20.

Khwan, A. A., Zaytsev, Yu. A., \& Kuznetsova, Yu. A. (2006). Standardized Questionnaire for Measuring Aggressive and Hostile Reactions by A. Buss and A. Durkey. Kemerovo: KRIPKiPRO.

Kogan, V. M. (1983). Social mechanism of criminal law influence. Moscow: Izdatel'stvo «Nauka».

Ludwig, A. W. (1969). Altered states of consciousness: A book of reading. N. Y.

Martsinkovskaya, T. D. (2009). Experience as a mechanism of socialization and identity formation c. today's changing world. Psychological research: electronic scientific journal, 3(5).

Pantileev, S. R. (1993). Self-Relationship Research Methodology. Moscow: Smysl.

Rodriguez, D. (2000). Self and adaptation: defining the healthy self. In The Inaugural SELF Research Centre International Conference: proceedings (pp. 355-365). Sydney, Australia.

Rogers, C. (2001). Becoming a Person. A look at psychotherapy. Moscow: EKSMO-Press.

Rogers, C., \& Freiburg, J. (2002). Freedom to study. Moscow: Smysl.

Rogov, E. I. (2020). Ethics and psychology of professional activity. Moscow: Urait Publishing House.

Rokich, M. (1973). The nature of human values. Free press, 5, 20-28.

Solovyeva, T. A. (2000). Theoretical Foundations of the Intellectual Developing Educational Process in Elementary School (Doctoral dissertation, Moscow State Pedagogical University, Moscow). Retrieved from https://rusneb.ru/catalog/000199_000009_003204813/

Solovyeva, T., \& Shiryaykina, O. (2015). Pedagogical Providing of Beginning of Intellectual Culture of the Juniors Taking into Account their Intellectual and Psychological Sex. SOCIETY, INTEGRATION, EDUCATION: Proceedings of the International Scientific Conference (pp. 196209). Rêzekne: Rêzeknes Augstskola. DOI: 10.17770/sie2015vol2.453

Solovyeva, T. A. \& Makarchuk, T. N. (2018). The study of the category "individual educational trajectory of a student in an inclusive education" from the point of view of the acmeological approach. Primary School, 9, 41-46. 
Stolin, V. V. (1983). Self identity. - Moscow: Izdatel'stvo Moskovskogo universiteta.

Vygotsky, L. S. (1984). Child psychology. Collection of Connections: in 6 volumes (Vol. 4). Moscow. 